\title{
Optic nerve metastasis from a mediastinal carcinoid tumour
}

\author{
MARTIN L. FISHMAN AND SUSAN ROSENTHAL* \\ From the Clinical Branch, National Eye Institute and the Medicine Branch*, National Cancer Institute, \\ National Institutes of Health, Bethesda, Maryland, USA
}

Carcinoid tumours arise from the enterochromaffin cells of tissues derived from primitive entoderm (Gosset and Masson, 1914). They have been described in the gastrointestinal tract, pulmonary bronchus, biliary system, pancreas, ovary, testis, and parotid gland (Peskin and Kaplan, 1969). Ocular metastases from these tumours have occurred, but in every case have originated from bronchial carcinoids (Southren, I960; Ricketts, Price, and Thomas, 1955; Rosenbluth, Laval, and Weil, 1960; Font and Kaufer, 1963; Honrubia, Davis, Moore, and Elliott, 1972; Fu, McWilliams, Stratford, and Kay, 1974; Bell, Bullock, and Albert, 1975).

An unusual mediastinal tumour, with features most consistent with a carcinoid neoplasm, has recently been described (Rosai and Higa, 1972). We present such a case in which clinical symptoms developed from metastases to the optic nerve. This is the first case of ocular metastasis from mediastinal carcinoid and the only case, of which we are aware, of carcinoid metastatic to the optic nerve.

\section{Material and methods}

\section{CASE REPORT}

A 25-year-old White man was found to have hilar and mediastinal adenopathy in October 1974 , after a history of recent weight loss, pleuritic chest pain, and pneumonia. Bronchoscopy and endobronchial brush biopsy were normal. A scalene lymph node biopsy and bone marrow examination showed metastatic tumour and the patient was referred to the National Cancer Institute for evaluation. No history of flushing, cyanosis, diarrhoea, abdominal cramping, or lacrimation was elicited. Physical examination revealed enlarged supraclavicular lymph nodes. Haematological and blood chemical evaluations were within normal limits, and urinary 5-hydroxy-3-indoleacetic acid levels were normal. Scalene lymph node and bone-marrow specimens were reviewed (see below) and a diagnosis of mediastinal carcinoid tumour was made based on the pathological and clinical findings.

Treatment was begun with cyclophosphamide and vincristine and a partial response was noted. By February 1975, however, symptoms recurred, hepatic metastases National Institutes of Health, Bethesda, Maryland 20014 USA, were demonstrated, and pulmonary tomograms showed further mediastinal widening. An enlarged scalene lymph node was biopsied for electron microscopical examination, and the patient was given palliative radiation therapy to the mediastinum followed by adriamycin chemotherapy. By May 1975 osteoblastic metastases were noted in the skull, ribs, and vertebrae and inguinal lymphadenopathy developed.

In July 1975, the patient noted blurred vision in the right eye. An examination revealed normal pupillary responses, full ocular motility, and no evidence of proptosis. The vision is reported to have been normal at this time, although an ophthalmologist was not consulted. Re-examination three weeks later showed disc haemorrhages and exudates to be present in the right eye. The vision in the right eye decreased rapidly to hand movements, and the patient died of severe respiratory difficulties four weeks after the onset of visual symptoms. The left eye was normal throughout the patient's illness.

\section{Histopathological findings}

\section{LYMPH NODE BIOPSY}

The lymph node was replaced almost totally by dense sheets of moderate size cells, arranged in parallel and anastomosing bands with occasional perivascular palisading. Multiple mitoses were present. The cells had scanty cytoplasm, with large nuclei, finely distributed chromatin, and inconspicuous nucleoli. Modest variation in the size and shape of individual cell nuclei was noted. Stains for neurosecretory granules were equivocal for argentaffin granules (Fontana's stain) but positive for argyrophilic granules (Bodian's silver stain).

Electron microscopical examination of glutaraldehyde fixed tissue revealed the presence of membrane enclosed circular and oval neurosecretory granules within the cytoplasm of the tumour cells. These contained a central core of homogeneous, electron dense material, surrounded by a small, electron lucent space (Fig. I). The cells tended to be arranged around small central limina into which a few microvilli projected. Many displayed prominent pseudopods and interdigitations. The cytoplasm contained dilated endoplasmic reticulum, abundant mitochondria, prominent Golgi apparatus, lipid droplets, and fibrils. Both dark and light cell types 


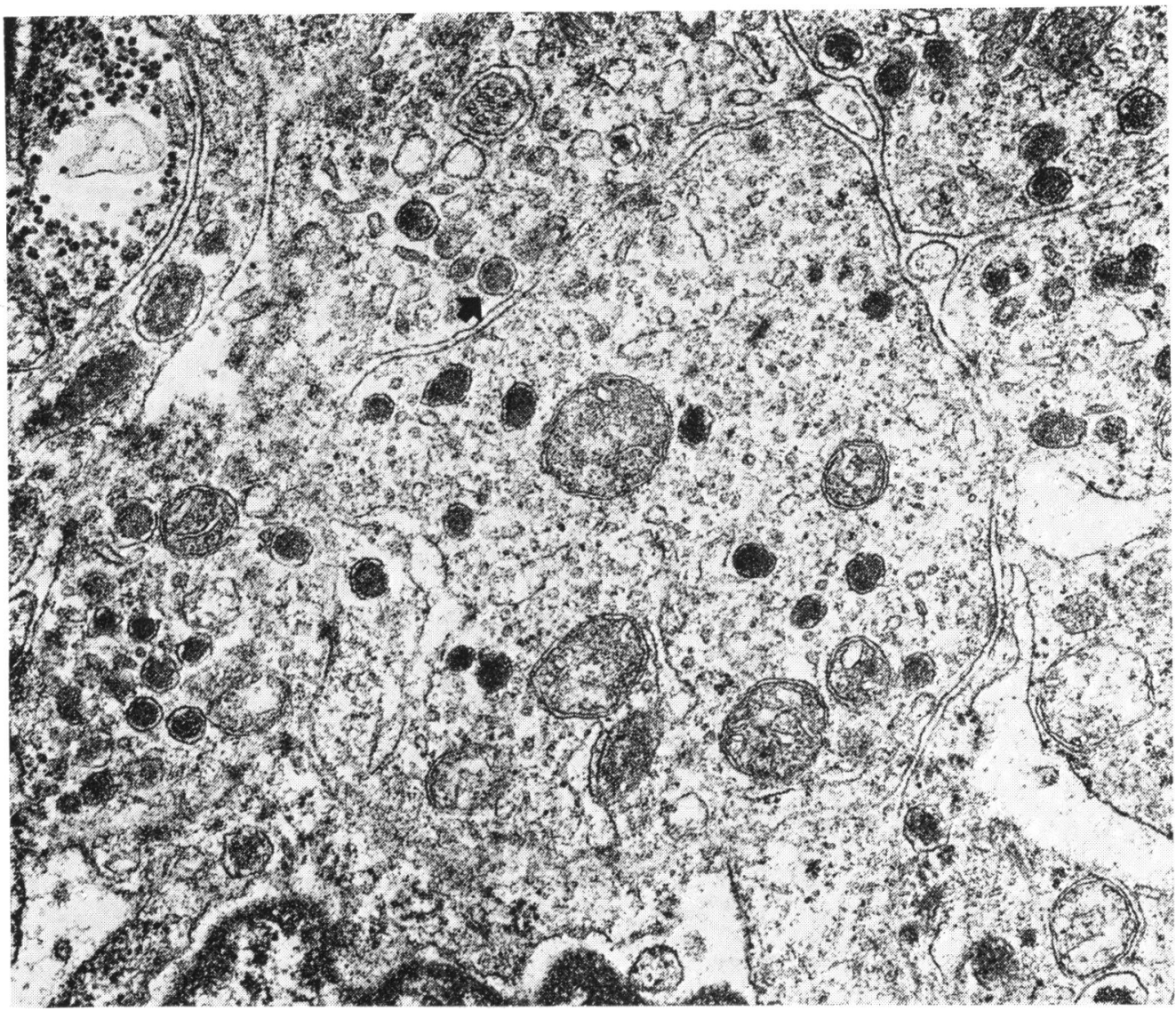

FIG. I Pseudopods of tumour cells containing mitochondrion and multiple circular secretory granules, characterized by a uniform electron dense central core with a small electron lucent space surrounded by a membrane (arrow). $\quad \times 25000$

were noted (Bensch, Gordon, and Miller, 1965) (Fig. 2).

\section{GENERAL NECROPSY FINDINGS}

Metastatic carcinoid tumour was present in the lungs, epicardium, mediastinum, axillary lymph nodes, liver adrenal glands, abdominal lymph nodes, colon, peripancreatic tissue, and vertebrae. No evidence of a bronchial or gastrointestinal primary was found, and the site of the tumour was believed to be the mediastinum.

\section{OCULAR FINDINGS}

The eyes were normal externally except for an enlarged right optic nerve $(7.1 \mathrm{~mm}$ diameter, compared with $4.6 \mathrm{~mm}$ in the left eye), with a normal optic nerve sheath and a patent subarachnoid space. The anterior segment of the right eye was normal, but the right disc was raised with superficial haemorrhages on its surface and a pale appearance of the disc tissue obscured the emerging retinal vessels. Scattered peripheral retinal haemorrhages were also present. The left eye was normal.

Microscopically, the anterior segment of the right eye was normal. Papilloedema of the right disc was present with peripapillary exudates and haemorrhages. Almost the entire retrolaminar optic nerve was replaced by fairly uniform, basophilic cells with scanty cytoplasm (Figs 3,4 ). These were densely packed, separated by multiple fine fibrovascular trabeculae, with a tendency towards palisading and rosette formation (Figs 5, 6). Several large areas of necrosis were present within the tumour. Stains for argyrophilic granules were equivocal, while argentaffin stains were negative. Electron microscopical examination of the optic nerve revealed cells similar to those in the examined lymph node.

\section{Discussion}

Previous reports of ocular metastase from carcinoid 


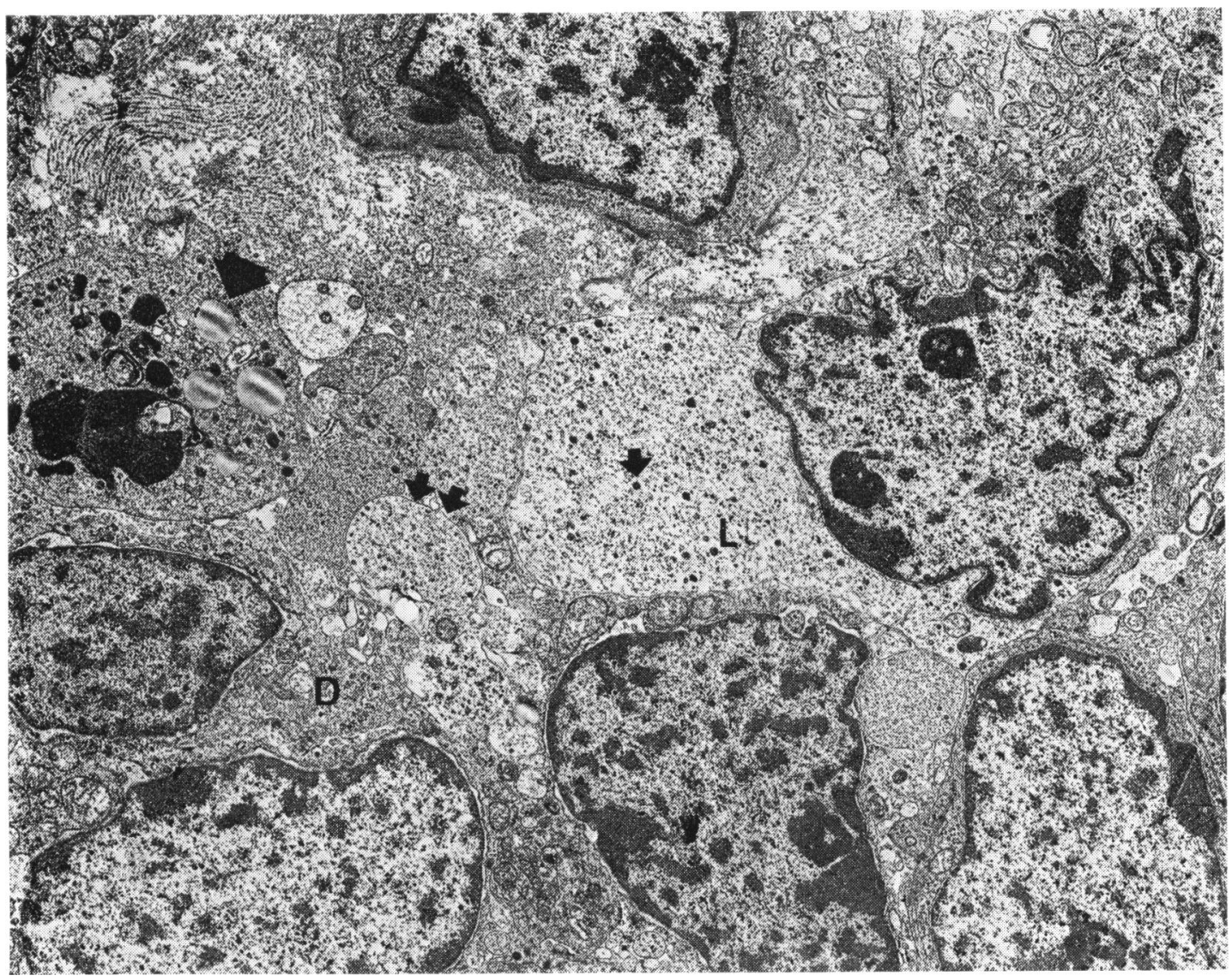

FIG. 2 Tumour cells with both 'light' (L) and 'dark' (D) cytoplasm, displaying multiple pseudopods (double arrozv). Cystoplasm contains neurosecretory granules (single arrow) and lipid droplets (broad arrow). $\times 4000$

tumours have been limited to bronchial carcinoids, which have involved either the choroid (Southren, 1960; Ricketts and others, 1955; Rosenbluth and others, 1960; Font and Kaufer, 1963; Fu and others, 1974; Bell and others, 1975) or orbit (Honrubia and others, 1972). Over 95 per cent of carcinoid tumours arise in the gastrointestinal tract, usually the small intestine or appendix, with the remaining 5 per cent taking their origin from other sites (Pesking and Kaplan, 1969). While the gastrointestinal tumours characteristically have a low malignant potential with very slow growth and late metastases, bronchial carcinoids have been found to metastasize in 10 to 15 per cent of cases (Tolis, Fry, Head, and Shields, I972) thus accounting for their occasional association with ocular metastases.

Rosai and Higa (1972) have recently presented a comprehensive description of primary carcinoid tumours of the mediastinum. In the cases summarized, all the patients were adults and most
(I4 to I6) were male. None of the patients developed the carcinoid syndrome (Sjoerdsma and Melmon, 1964). Many presented with minimal symptoms, and tumour progression occurred slowly. A more aggressive form of this tumour, also arising in the mediastinum but associated with multiple endocrine adenomatosis (Rosai, Higa, and Davie, 1972), was described in three additional cases. Metastases occurred to bone, gastrointestinal tract, lung, lymph nodes, and adrenal glands and caused death in each of the patients. Ocular metastases were not described. The present case thus has features characteristic of both types of mediastinal carcinoid tumours.

Mediastinal carcinoids, as described by Rosai and others (1972) and exemplified by the present case, have histological features similar to carcinoid tumours of other tissues. A useful subclassification of these neoplasms by their embryonic site of origin (Williams and Sandler, 1963) emphasizes the differences of foregut, midgut, and hindgut carcinoids. 


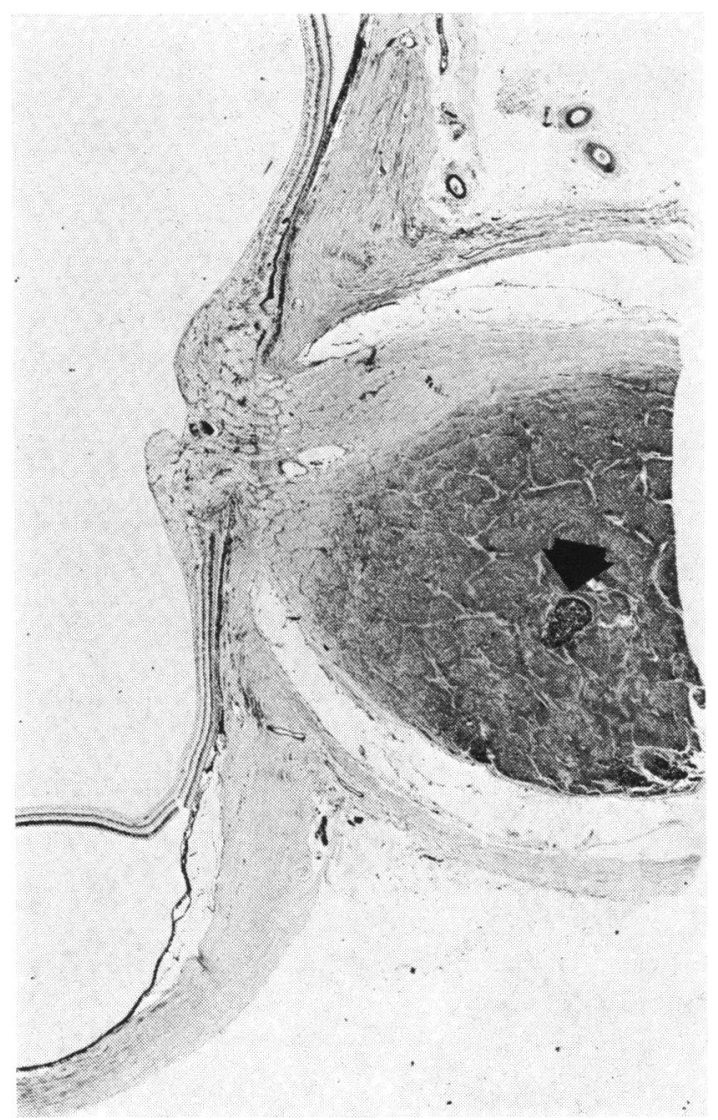

FIG. 3 The retrolaminar optic nerve is almost totally replaced by tumour cells. Papilloedema is present, and there is an area of necrosis within tumour (arrow). Haematoxylin and eosin. $\times 10$

Those of foregut origin (bronchus, pancreas, stomach, and mediastinum) tend to have a trabecular pattern and reduce silver only in the presence of an exogenous reducing agent (positive argyrophilic staining, negative argentaffin stain). The characteris- tic secretory granules of these foregut tumours are small, round, electron dense deposits, surrounded by a clear zone and a unit membrane (Hage, 1973; Black, 1968). Carcinoid tumours of midgut and hindgut origin present somewhat different characteristics, as summarized in the Table. The histological pattern, argyrophilic staining, and ultrastructural findings of small, round uniform secretory granules in the present and similar cases (Broderick, 1973; Manes and Taylor, 1973) would support a foregut derivation.

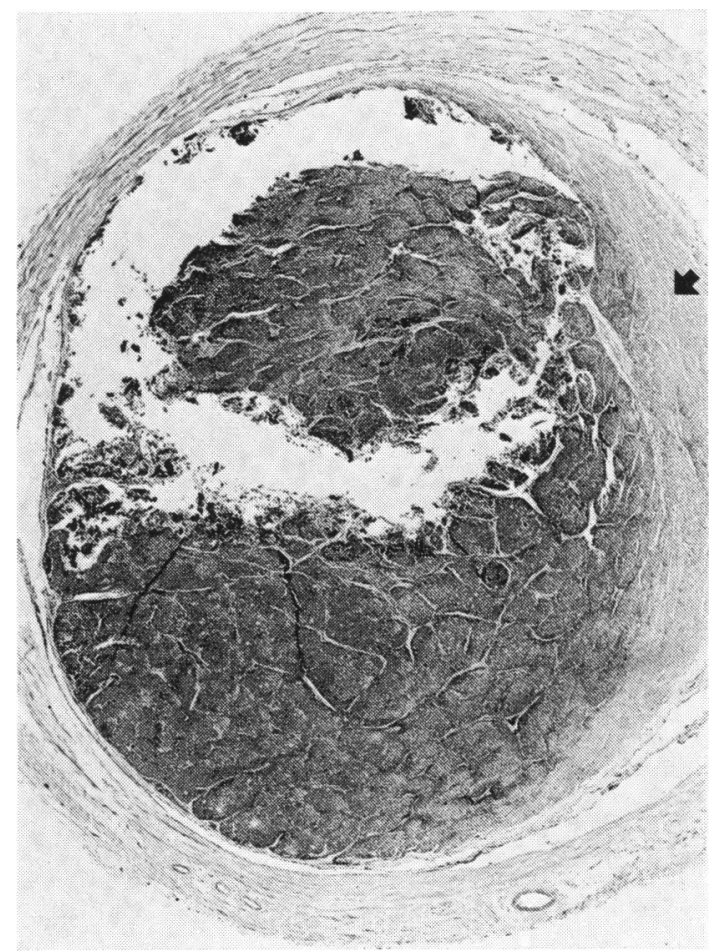

FIG. $4 A$ cross-section of optic nerve shows normal nerve tissue present only peripherally (arrou). Haematoxylin and eosin. $\times 14$

Table Carcinoid tumour characteristics according to gut derivation

\begin{tabular}{|c|c|c|c|}
\hline & Foregut & Midgut & Hindgut \\
\hline Tissue & $\begin{array}{l}\text { Lung, pancreas, stomach, } \\
\text { mediastinum }\end{array}$ & Small intestine, ascending colon & Descending colon, rectum \\
\hline Histology & Trabecular & Classical 'nests' & Trabecular \\
\hline Argyrophil & Positive & Positive & Negative \\
\hline Argentaffin & Usually negative & Positive & Often negative \\
\hline Granule ultrastructure & Uniform, small, round & $\begin{array}{l}\text { Pleomorphic, large uniform or } \\
\text { dense central cores; rounded, } \\
\text { variable size and density }\end{array}$ & Rounded, variable density \\
\hline Metastases & Common & Rare & Common \\
\hline
\end{tabular}


While the origin of mediastinal carcinoid tumours is not clear, it has been suggested that the thymus may give rise to this tumour. Cells similar to the Kultschitsky cell of the intestine have been found in the thymus of some animals (Reggiani, 1946; Toró, Oláh, Röhlich, and Viragh, 1969), argyrophilic cells have been found in human thymus (Rosai and Higa, 1972), and neurosecretory granules have been reported in human thymus by electron microscopical examination (Koss, 1970).

Treatment for carcinoid tumours has been primarily surgical with chemotherapy reserved for those cases in which widespread metastases have been presented (Davis, Moertel, and McIlrath, 1973). Although radiotherapy has been used to treat

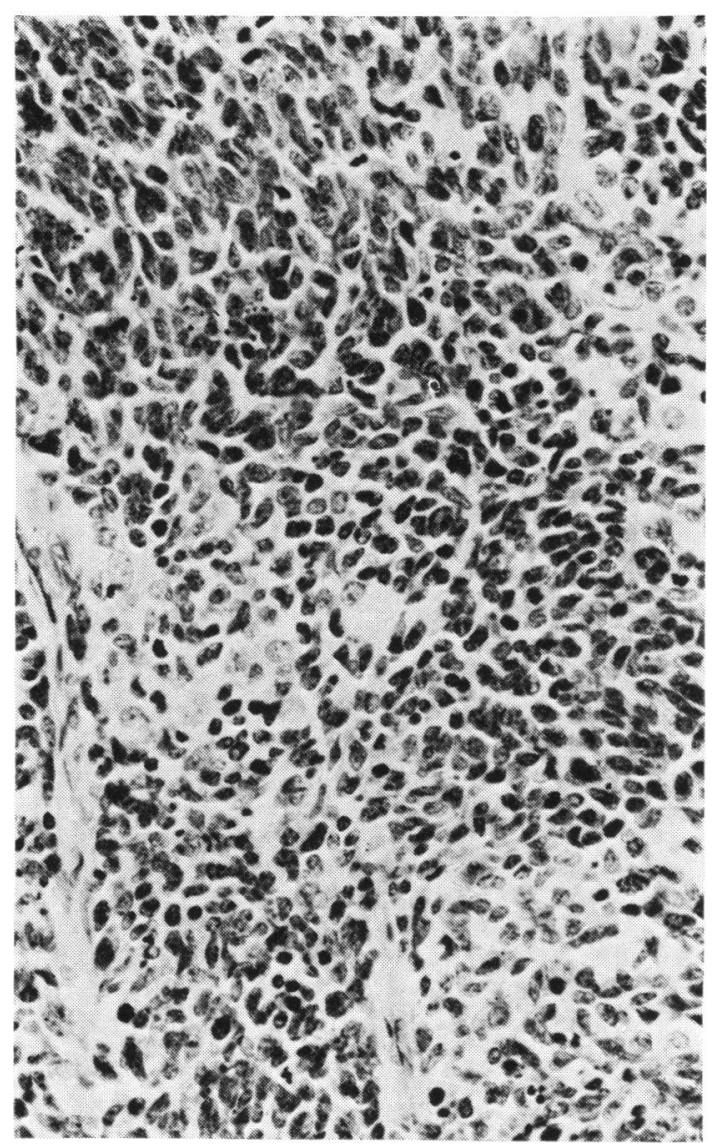

FIG. 5 The tumour cells are divided by fibrovascular strands. Haemotoxylin and eosin. $\times 350$

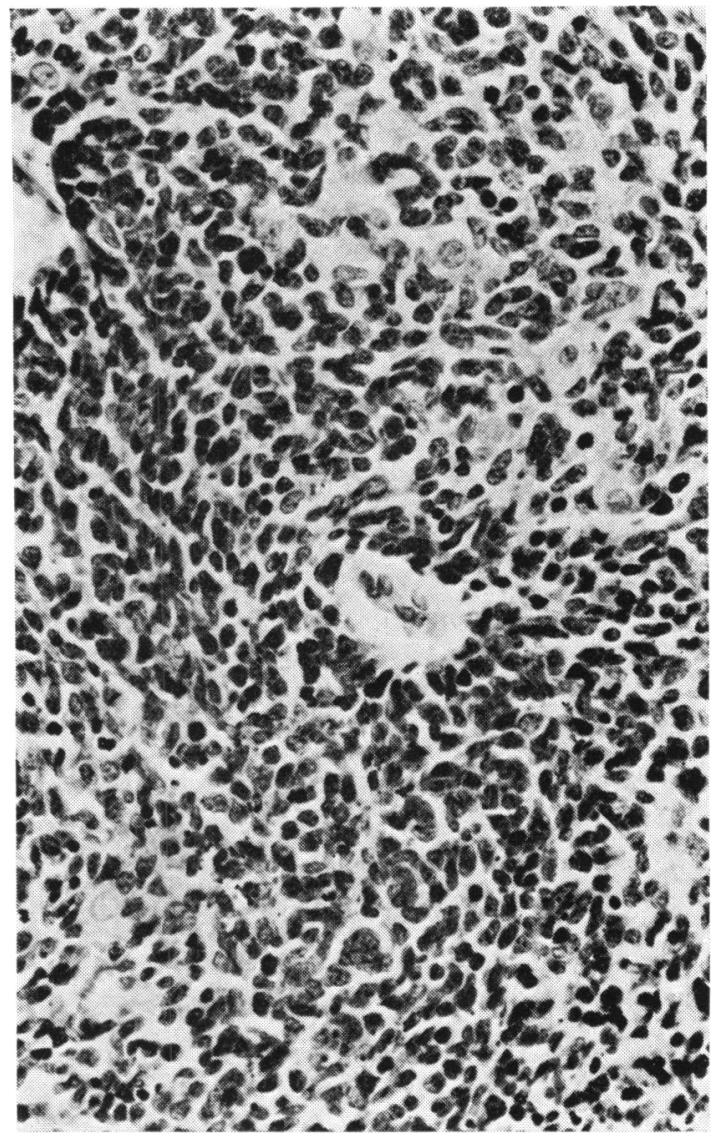

FIG. 6 In some areas, pseudorosette formation is demonstrated. Note moderate degree of pleomorphism of the tumour cell nuclei. Haematoxylin and eosin. $\quad \times 350$

metastases from these tumours, they are usually radioresistant (Martin, 1970). Enucleation has thus been advocated for progressive intraocular metastases (Bell and others, 1975).

\section{Summary}

A 25-year-old man with a rapidly progressive metastatic carcinoid tumour arising in the mediastinum developed a metastasis to the optic nerve. This is the first instance in the literature of an ocular metastasis from this variant of carcinoid tumour. The ocular pathology, ultrastructure, and recent information on the derivation of this tumour, believed to originate in the thymus, are presented.

\section{References}

BELl, R. W., BULlOCK, J. D., and ALBERT, D. M. (1975) Brit. F. Ophthal., 49, I 55 BENSCH, K. G., GORDON, G. B., and MILlER, L. R. (1965) Cancer (Philad.), 18, 592 BLACK, w. C. (1968) Lab. Invest., 19, 473 
BRODERICK, P. A. (1973) F. thorac. cardiovasc. Surg., 65, 134

DAvis, z., MOERTEL, C. G., and MCILRATH, D. c. (1973) Surg. Gynec. Obstet., 137, 637

FONT, R. L., and KAUfER, G. (1963) Amer. Y. Ophthal., 62, 723

FU, Y. S., MCWilliams, N. B., STRATFORD, T. P., and KAY, S. (1974) Cancer (Philad.), 33, 707

Gosset, A., and MASSON, P. (1914) Presse méd., 22, 237

hage, E. (1973) Virchows. Arch. path. Anat., 36r, 121

hONRUBia, F. M., DAVIS, w. H., MOORE, M. K., and ElliotT, к. J. (1972) Amer. F. Ophthal., 72, I 118

Koss, L. G. (1970) 59th Annual Meeting of the International Academy of Pathology, St Louis, MO, Io March MANES, J. L., and TAYLOR, H. B. (1973) Arch. Path., 95, 252

MARTIN, R. G. (1970) Cancer (Philad.), 26, 547

PESkin, G. W., and Kaplan, E. L. (1969) Surg. Clin. N. Amer., 49, I 37

REgGIANI, M. (1946) Boll. Soc. ital. Biol. sper., 22, 108

ricketTS, M. M., PRICE, т., and thomas, M. (1955) Amer. F. Ophthal., 39, 33

ROSAI, J., and HIGA, E. (1972) Cancer (Philad.), 29, 106 I

,-- , and DAVIE, J. (1972) Ibid., 29, 1075

rosenbluth, J., laval, J., and Weil, J. v. (1960) Arch. Ophthal., 63, 47

SJOERDSMA, A., and MELMON, K. L. (1964) Gastroenterology, 47, 104

SOUTHREN, A. L. (1960) f. clin. Endocr., 20, 298

TOLIS, G. A., FRY, W. A., HEAD, L., and SHIElDS, T. W. (1972) Surg. Gynec. Obstet., 134, 60 I

TORó, I., Oláh, I., RöHlich, P., and Viragh, s. (1969) Anat. Rec., 165, 329

WILliamS, E. D., and SANDLER, M. (1963) Lancet, I, 238 